\title{
In vitro babies - medical and legal aspects: a European and North American perspective
}

\author{
JANUSZ GadZinOWSKI ${ }^{1 *}$, T. Allen MerRitT ${ }^{2}$, ALEKSANDRA JOPEK ${ }^{3}$, \\ ANDRZEJ KoChANSKI ${ }^{4}$, AdRIAN LAVERY ${ }^{2}$, TRAVIS MERRITT ${ }^{1}$ \\ ${ }^{1}$ Department of Neonatology, Poznan University of Medical Sciences, Poznań, Poland \\ ${ }^{2}$ School of Medicine, Department of Pediatrics, Division of Neonatology, Loma Linda University, Loma Linda, California, USA \\ ${ }^{3}$ Department of Neonatal Infectious Diseases, Poznan University of Medical Sciences, Poznań, Poland \\ ${ }^{4}$ Neuromuscular Unit, Mossakowski Medical Research Center, Polish Academy of Sciences, Warszawa, Poland \\ *Corresponding author: jgadzin@gpsk.am.poznan.pl
}

\begin{abstract}
On the basis of observations in Europe and North America, this review will focus on Assisted Reproductive Technologies (ART) and their impact on pregnancy outcomes; in particular multiple births, prematurity, and their impact on birth defects. In Europe, since 1985 this experience has been somewhat different from that in North America due not only to the differing populations, cultures, religious perspectives, but also to the rapid implementation of medical technologies, relative freedom from governmental regulation, as well as the different forms of payment for medical care that exist between the two continents. This review will focus on the impact of ART on the complications of pregnancy, multiple gestations and prematurity, and will evaluate the required process and content of informed consent surrounding ART from the legal perspective. Issues related to complications resulting from the use of ART from the perspective of neonatal care providers will be highlighted as well as its impact on the health care system in both regions. Given the impact of ART on both sides of the Atlantic, we propose that governments, as well as professional organizations - including reproductive specialists, neonatologists, and health economists - recommend that a legal limitation on the number of embryo transfers be imposed and that embryo transfer restrictions be coupled with reimbursement for ART services. We suggest that reproductive rights should not be infringed but that greater concern for and monitoring of the safety of both mothers and their newborns be undertaken by various professional organizations and governments in Europe and North America. We also propose systematic centralized reporting of the effectiveness of each form of ART, along with any associated complications, and that ART babies be carefully monitored for birth defects and imprinting disorders on both continents.
\end{abstract}

Key words: Assisted Reproduction Technologies (ART), prematurity, multiple gestation, imprinting disorders, birth defects, newborn safety, congenital malformation, ART outcomes

With more than a 30 year history, in vitro fertilization and other forms of assisted reproductive technologies have expanded and gained widespread use in $\mathrm{Eu}-$ rope and North America. However, multiple ethical and legal controversies exist in many European countries. There has been limited legal regulation of these expanded practices (e.g. IVF, ICSP, donor oocytes, number of embryos transferred etc.) that constitute the assisted reproductive technologies (ART) in current use. The Council of Europe meeting held in Oviedo in 1997 gathered participants from 47 countries and created the "Convention for the Protection of Human Rights and Dignity of the Human Being with regard to the Application of Bio- logy and Medicine: The Convention on Human Rights and Biomedicine" more widely known as the "European Bioethical Convention". This convention outlined the basic standards on the most controversial aspects of ART. The major concerns were focused on the prohibition of the creation of human embryos for research purposes, the prohibition of embryo preselection for the selection of gender, and the prohibition of interference with the human genome for purposes other than prophylactic, therapeutic or diagnostic (http://conventions.coe.int/ Treaty $/ \mathrm{html} / 164 . \mathrm{htm}$ ). The provisions of the Convention were only a "recommendation" and therefore required ratification by members of the Council of Europe, which 
were to commit themselves to enact these provisions into their own legal frameworks to provide for legal authority within each respective country.

Currently, 22 countries have ratified the guidelines of the Convention (http://www.prawoimedycyna.pl/index. php?str=artykul\&id=250). The remaining countries have distanced themselves from endorsement of the major guidelines of the Convention and have determined their own legal regulations. In some instances their decisions were based on the European Union directives concerning the conduct of research with reproductive cells and human embryos created during in vitro fertilization (Directive 2004/23 - Official Journal of the European Union). Only 5 European countries have not enacted legal regulations concerning ART, i.e. Poland, Andorra, Cyprus, Romania and Serbia. The legislative framework of each country is different in respect to, among other things, the number of embryos created, the limitations on use for other than reproductive purposes, the legal status of the embryo, the possibilities for embryo selection, and the use of embryos not transferred for human reproduction. Other issues that have been addressed include the availability of ART to unmarried women, homosexual couples, and the issue of who pays for these procedures - individuals or national health systems within these countries. As a result, legislation has varied throughout Europe from the very liberal with few restrictions as in the United Kingdom or parts of Scandinavia, to the more highly restrictive policies in Germany, Italy, Sweden, and Belgium.

In practice, these different legal restrictions and the variable controls placed on ART make it difficult to standardize the quality of services concerning the securing and use of human cells, tissues or organs, the organizational requirements, or the capacity to provide these procedures to those desiring them. In the absence of such standards, it has been difficult to thoroughly analyze the results of ART as it relates to effectiveness, and rates of success by procedure, and to review the number of primary and repeated procedures, and possible complications to both women and, very importantly, infants conceived using ART. In addition, the financial cost to families and the burden to national health budgets in many countries are difficult to compare. Furthermore, the use of ART by citizens of one country traveling to a neighboring or distant country ("medical tourism") has been difficult to monitor. As a result, legal authorities in several countries have suggested that a common policy on ART be developed for use throughout Europe.

The European Society of Human Reproduction and Embryology (ESHRE) has supported the concepts of Nobel Laureate Dr. Robert Edwards regarding the stimulation of research and standardization of ART procedures. ESHRE has also made efforts to monitor and to some degree "control" the "in vitro market" throughout Europe. The major aim of this review is to evaluate the medical services offered as a part of ART, and to provide a broader examination of the effectiveness and success rates of individual centers. Such analyses provide information regarding the effectiveness of individual ART procedures as well as complications occurring in the perinatal period concerning the mother, the embryo, and the newborn, and the later influences on the health and well-being of the mother and the child delivered as a result of ART or artificial insemination.

Although the population of Europe exceeds 600 million, being some $15 \%$ of the global population, approximately $60 \%$ of the world's centers for ART and artificial insemination are located within Europe. Thus, an analysis of such an extensive number of centers and their datasets should stimulate the formation of a standardization of protocols in terms of "outcome reporting" or assessment of differential "success rates", and provide for a central reporting mechanism for complications to both mothers and infants. A secondary goal is to provide a comparison of the costs of ART throughout the continent. Such a central database, similar to those developed in the U.S. by the Centers for Disease Control and Prevention, would ultimately provide important data for families seeking ART services, health-policy authorities within governments, and officials responsible for financing health care delivery throughout European states. These goals need to be implemented as soon as possible.

Data from the 1997 ESHRE report involving 18 countries and 482 fertility centers, the majority of which had implemented internal registries, have been incorporated into the $2005 \mathrm{ESHRE}$ report that now includes 30 countries and 923 centers, and serves as the major repository of ART data within Europe. Initially, the reported data included ART procedures such as IVF, ICSI, information on the use of donor oocytes, transfer and storage of frozen embryos, the effectiveness of ART expressed as ultrasound confirmed pregnancy, the number of live births, and the age distribution of mothers. 
However, over time these datasets were expanded to include more procedures including insemination with semen from the spouse/partner (IUI-H) or from a donor (IUI-D). Recently obtained additional information on genetic pre-implantation diagnoses (PGD) is now also included.

In 1997 more than 200,000 procedures were reported to the ESHRE. These data documented 18,899 gestations from which 24,283 children were born. The percentage of single births was 70.7 after IVF, and 71.7 after ICSI. Twins occurred in $25.8 \%$ of pregnancies resulting from IVF and $25.2 \%$ of pregnancies occurring after ICSI. In $3.6 \%$ of pregnancies after IVF triplets resulted, and 2.9\% occurring after ICSI, with quadruplets occurring in $0.2 \%$ of gestations resulting from IVF and $0.1 \%$ after ICSI. Based on complete data from 10 countries, it has been extrapolated that for every one million of Europe's population there were on average $765 \mathrm{ART}$ procedures resulting in $1.33 \%$ of all births per year. By 2005 the number of registered cycles had reached 320,000 , of which $36 \%$ resulted from IVF with the remaining from ICSI of the pregnancies, with the result that $78.2 \%$ of women gave birth to singletons, $21 \%$ had twins, and $0.8 \%$ resulted in triplets.

With recent recommendations calling for a reduction in the number of multi-fetal pregnancies and the risks associated with them, there has been an apparent trend to reduce the number of embryos transferred. While in 1997 only $11.5 \%$ of pregnancies resulted from single embryo transfer (SET), double embryo transfer (DET) occurred in $39 \%$ of cases, while in $38.4 \%$ three embryos were transferred, and in $14.3 \%$ three or more embryos were transferred. By 2005 SET took place in $20 \%$ of procedures in Europe with the greatest number occurring in Sweden (i.e. 65\%). However, of all transfers in Europe, DET represented 56\% of these procedures, and triple embryo transfer occurred in $21 \%$. Three or more embryo transfers occurred in only $2 \%$ of procedures performed. The effectiveness of ART measured using an ultrasound confirmed pregnancy and live-birth differed by ART technique. While in vitro fertilization resulted in $26.1 \%$ pregnancies with $20.9 \%$ live-births, with ICSI there was $26.4 \%$ pregnancies resulting in $21.5 \%$ livebirths. By 2005, ART had risen to 1115 procedures per 1 million of population with $30.3 \%$ of pregnancies resulting from IVF and $30.9 \%$ from ICSI. Thus, despite the rapid growth in the number of procedures performed, and the overall effectiveness of these procedures in Europe, this was less than the growth in U.S. where $42 \%$ of wo- men receiving ART had a confirmed pregnancy with some $27 \%$ of U.S. women having a live-birth (Nygren and Nyboe Andersen, 2001; de Mouzon et al., 2010).

The importance of having a European registry is to persuade and assist many fertility centers that offer ART to actively report to a central database for meaningful comparisons of efficacy and safety, as well as the "quality" of various providers. This is especially important for those countries that do not maintain a registry of mothers and the offspring conceived using ART (including Poland). While the European monitoring system included 30 countries in 2006, there remain significant differences in the scope and use of ART, the proportion of methods used in some countries, differences in the effectiveness of each method, and the age distribution of mothers seeking services at individual centers as well as the number of single or multiple births that result from ART. While a central professional registry has limitations, including incomplete data and the lack of reporting from several countries or indeed incomplete recording of complications occurring in either women or their children, the database has provided useful information. However, this information could be improved substantially.

After the initial euphoria of the late 1970s and early 1980 s and the increase in the number of infants born using ART technologies, it was also noticed that untoward and unwanted complications were occurring in some women and in the infants born after ART. Some of these problems were not diagnosed until later childhood. Thus, any risk assessment must include not only complications occurring or resulting from pregnancy after ART, but also the prevalence of prematurity and multiple gestations, and also the health status of the infants born, and malformations identified in the neonatal period.

According to the majority of reports, the risk of spontaneous abortion after ART does not exceed the total population risk and approximates 15\% (http:// www.uptodate.com/store). The ESHRE report from 2006 showed that ART was associated with a pregnancy loss of 9 percent (de Mouzon et al., 2010). It is unclear whether the number of pregnancies lost presented in the ESHRE report also included spontaneous abortions, as well as medical termination of pregnancies. As shown in the MOSAIC project (Models of Organizing Access to Intensive Care for the Very Preterm Baby), based on an analysis of data concerning all births between 23 to 31 weeks gestation from 10 regions in 9 European count- 
ries, termination of pregnancy occurred in $0.5-17.6 \%$ of all pregnancies depending on the region. The most common reason given for termination in all countries was for congenital anomalies (80\% of cases) (Papiernik, 2008). Taking in account that pregnancies resulting from ART have a $40 \%$ higher risk of certain malformation than in the general population, information on birth defects in the population of children born after IVF needs to be completed in order to have combined data on the prevalence of specific birth defects, spontaneous abortions, terminations of pregnancy, need for fetal reduction, as well as live births. It is noteworthy that pregnancies resulting from ART double the risk of ectopic pregnancy compared to those conceived naturally, and increase the risk of heterotrophic pregnancies (1 per 100 with ART versus 1 per 30,000 naturally conceived) (http:// www.uptodate.com/store).

Maternal complications after ART include ovarian hyperstimulation syndrome, a larger percentage of ovarian torsion, preeclampsia, pregnancy induced hypertension, diabetes, vaginal bleeding, placenta previa and premature rupture of the fetal membranes (Kallen et al., 2005; Finnstrom and Kallen, 2011). Newborn complications are related to the higher frequency of multiple gestations, prematurity, low birth weight, congenital malformations, chromosomal anomalies, and other genetic diseases. Neonatal death rates after ART are three fold higher than among infants conceived naturally (Basso and Olsen, 2005; Helmehorst et al., 2004). The majority of these complications are related to the significantly increased number of multiple gestations resulting from ART procedures where some $25 \%$ of all pregnancies are twin pregnancies. Indeed $40 \%$ of all infants born after ART are from multiple gestations (Land and Evers, 2003). These results are comparable to those reported in the U.S., where the number of twin gestations increased to over $40 \%$ following ART, while, disturbingly, the number of higher order multiples (three or more) increased 5-fold (Reynolds et al., 2003).

Multiple pregnancies associated with ART may result from ovarian hyperstimulation as well as the transfer of more than SET. These multiple pregnancies also pose risks to the mother, the fetus, and the newborn. For example, among mothers at risk with multiple pregnancies there is an increased risk of cardiovascular disease, hematologic disorders, preeclampsia, diabetes during pregnancy, postpartum bleeding with the require- ment for either surgical intervention or transfusion of blood products. Newborns delivered after multi-fetal gestation constitute $14 \%$ of all premature births and $21 \%$ of infants born with low birth weight (Blickstein and Keith, 2002; Blickstein, 2002). Prematurity and low birth weights are associated with a number of well established complications that impact on the child not only during the newborn period and early childhood, but (indeed) throughout their entire life. Premature infants present a higher occurrence of respiratory illnesses, mostly respiratory distress syndrome, but also the chronic lung disease - bronchopulmonary dysplasia. In addition, prematurity is too frequently associated with an increased risk of necrotizing enterocolitis, renal disease, and damage to the central nervous system. About $70 \%$ of all deaths occurring during the perinatal period result from premature birth, and the later development of these infants as children (especially those resulting from multiple births) are a larger burden to their parents and the health care system than infants born closer to term and as single live born infants. Of major concern is the high rate of cerebral palsy (an 8 fold increase) from twin births compared to singleton births, and especially as in the case of the demise of one twin the rate of cerebral palsy increases even 15 fold (Cook et al., 2011).

There also exist unique risks to monozygotic pregnancies or those resulting from the split of one embryo into two genetically identical embryos. This risk primarily occurs when the division takes place 4 days after fertilization to form monozygotic, monochorionic twin pairs. These twins are associated with more frequent placental pathology especially those associated with abnormal vascular connections in the placenta that connect the circulatory systems, and thus the cardiovascular systems, of each twin. This disorder is termed "twin-totwin transfusion syndrome". Twin-to-twin transfusion results in the exchange of blood from one twin (the donor) to the other twin (the recipient). The donor twin develops anemia, hypoxemia, and intrauterine growth restriction, while the recipient twin shows symptoms of cardiac overload resulting from hypervolemia, and polycythemia (often with thrombo-embolic phenomena) (Denbow et al., 2000; Revinis and Johnson, 1994). Pregnancies with monozygotic twins also pose a greater than normal risk of malformations compared to dizygotic twins. Furthermore, in monozygotic twin pregnancies there is a characteristic group of disorders occurring 
during the first 4 weeks after fertilization and associated with blastogenesis associated birth defects, which include neural tube defects, defects in the gastrointestinal tract specifically tracheoesophageal fistulae, and anal atresia (Halliday et al., 2010). While the frequency of monozygotic twin pregnancies is relatively stable in the general population $(0.4 \%)$, among those receiving ARTs the rate is $1.4 \%$. Although the mechanism causing the division of a single zygote to divide into two embryos is currently unknown, in ART the risk of monozygotic twin pregnancy is increased and is most likely related to the stimulation of ovulation and micromanipulation of the zona pellucida during the in vitro fertilization procedure (Engmann et al., 2001).

In addition to complications arising in mothers, complication rates for infants born after ART are primarily related to the high rate of multiple gestation pregnancies generated by ART and their high rates of prematurity. Steps must be taken to minimize multiple pregnancies primarily by reducing the number of embryos transferred to a single embryo and by reducing the hormonal ovarian stimulation used for oocyte retrieval to improve their outcomes. While in the early 1980s multiple embryos were transferred to improve the effectiveness of ART, an initial limit was placed to no more than three. In 1991 , in accordance with the recommendations of the $\mathrm{Hu}$ man Fertilisation Embryology Authority (HEFA), in Great Britain a three embryo transfer limit was established. However, the work of Engmann et al. (Engmann et al., 2001) found that the effectiveness of ART prior to and after the imposition of the three embryo limit was accompanied by no change in the number of multiple gestation pregnancies that occurred $-\sim 30 \%$. One of the reasons for this high rate of multiple pregnancy was the use of excessive ovarian stimulation in hormone treatments to the prospective mother, and the maternal age (older women had more embryos transferred with a tendency of 3 or more). On the other hand, the increase in the number of births after using ART primarily resulted from the selection of "higher quality" embryos by embryologists who evaluate those "created" during IVF or ICSI. The next step was to reduce the number of embryos transferred from two (DET), and now according to current recommendations to only one embryo or SET. The practice of restriction to SET is currently the standard in 5 European countries (http://www.eshre.eu/ESHRE/English/GuidelinesLegal/ESHRE-Position-Papers).
Swedish infertility specialists have followed the recommendation for SET very closely with the aim of reducing multiple pregnancies. For over 25 years there has been an obligation to report all ART procedures, and from the mid 1990s the policy of SET has been the Swedish standard. This had led to the impressive result of reducing the number of multiple births from $30 \%$ in 1991 to 6\% in 2006 (Nygren et al., 2001; Nygren and Nyboe Andersen, 2001; Nygren and Nyboe Andersen, 2002; de Mouzon et al., 2010). In 2011, Swedish scientists published the results of 25 years of analyses in using ART procedures, and their influence on the health of women and their offspring. Two time periods, 19821991 and 2001-2006, were compared (Kallen et al., 2005; Finnstrom and Kallen, 2011). The major difference in practice was the number of embryos transferred with $70 \%$ being SET in the latter time period versus $9 \%$ in the former period. Other changes occurred such as the increase in ICSI frequency that occurred in the latter period contrasting with classical in vitro fertilization, as well as a general lowering of the age of women seeking infertility treatment.

Thanks to this spectacular reduction in the number of multiple pregnancies from $30 \%$ in 1997 to $6 \%$ in 2006 (Nygren et al., 2001; Nygren and Nyboe Andersen, 2001; Nygren and Nyboe Andersen, 2002; de Mouzon et al., 2010) the percentage of complications occurring in both the mother and the newborn have been substantially reduced; however, this population still carries a higher risk than the general population. The frequency of premature birth in 2006 was $10.9 \%$ for ART infants compared to $6 \%$ of the general population conceived naturally, with the risk of prematurity in singletons of $7.5 \%$ compared to a population risk of $5.1 \%$. Low birth weight occurred in $7.5 \%$ of ART infants compared to $2.1 \%$ of those conceived naturally. There remained a greater risk of intraventricular hemorrhage, neonatal seizures, and respiratory distress requiring mechanical ventilation among infants conceived using ART compared to those conceived naturally. Congenital malformation risk, primarily associated with disorders of the cardiovascular system, musculo-skeletal system, was increased overall, and there was a small decrease in neural tube disorders, esophageal atresia, or cardiac septal disorders compared to the earlier period with multiple embryo transfer. There was also a decrease in cleft palate, imperforate anus, and hypospadias during the later period. Long-term complica- 
tions including cerebral palsy, developmental disorders, lower visual acuity, and asthma were diagnosed more frequently among infants delivered after ART than those born after natural conception. During the compared periods no differences in outcomes have been documented between ICSI or in vitro fertilization. However, there continues to be an increase in the risk of preeclampsia, premature rupture of the membranes, prematurity, and more caesarean sections among women receiving ART (Kallen et al., 2010).

The issues identified in Europe have also been identified in North America although magnified in terms of the disregard for professional standards in the case of the "Octomom", and the creation of surrogate pregnancies in which there is a paid surrogate womb for incubation of embryos that have been created by other means. It has recently been documented that some of these women are being sent to Europe (Ukraine specifically and perhaps other European countries) for donated embryo transfer after ovarian stimulation and then completion of the pregnancy within the U.S. with subsequent "selling" of babies to vulnerable parents. Complicating the North American experience is the fact that most health insurance policies, and many publicly paid plans (Medicaid in the U.S.) do not cover ART procedures, and in Canada only Quebec provides government paid but albeit limited ART services.

In the United States, Assisted Reproductive Technologies (ART) are responsible for $16.2 \%$ of twin deliveries and $38.3 \%$ of triplet deliveries (Wright et al., 2008). ART has been implicated in contributing disproportionately to the failure to achieve significant reductions in premature births. ART is available not only for infertile couples, but also for women seeking pregnancy without a male partner, and to men who choose to have a child through the use of surrogate gestational carrier who agrees to carry a pregnancy using either her own egg(s), or an egg/eggs obtained from another woman. In 1905, in an era preceding ART by seven decades, the United States Supreme Court found, in Jacobsen v Massachusetts, that limitations on personal liberty for the purposes of the public health were permissible. The Court held that "persons and property are subjected to all kinds of restraints and burdens, in order to secure the general comfort, health, and posterity of the State; of the perfect right of the legislature to do which no question ever was, or upon acknowledged general principles ever can be made, so far natural persons are concerned" (United States Supreme Court, 1905). In 1977 the United States Supreme Court ruled that the decision to bear children is constitutionally protected, and thus ART differs from other areas of medicine (United States Supreme Court, 1977). President Carter appointed an Ethics Advisory Board that issued a report in 1979 suggesting that a permanent board should be appointed to monitor ART. Their recommendations were never implemented.

In 1992, Congress enacted the Fertility Clinic and Success Rate and Certification Act that required the Secretary of Health and Human Services, through the Centers for Disease Control and Prevention, to develop a model program for the certification of embryo laboratories. This was to be carried out voluntarily by interested States. Thus, voluntary reporting by Fertility Clinics was established, but no specific mandate for reporting was established. Beginning in 1997, the Centers for Disease Control and Prevention (CDC) issued 12 annual reports detailing the clinical outcome of ART programs (http://www.ced.gov/ART/). To comply with the law, the CDC established a quality control program that reviews the incoming, voluntarily submitted data and performs annual site visits. Rather than individual physician performance, clinic-specific pregnancy and live birth success rates based on ART modality and maternal age are collected. Information collected includes live birth rate per initiated ART cycle, per oocyte retrieval, and per embryo transfer. The $\mathrm{CDC}$ also reports on the accreditation status of attendant embryo laboratories and the identity of non-reporting programs (Adashi and Wyden, 2011). While these reports may be used as "quality indicators" of clinic performance, "chief among those improvements is the incidence of multiple births, an outcome driven by the number of embryos transferred in the course of an ART cycle." A comparison of the U.S. national patterns of practice in 1997 with those in 2008 establishes that the percentage of cycles entailing the transfer of 3 or more embryos decreased from $83 \%$ to $35 \%$ (the CDC report). Unfortunately, $8 \%$ of ART programs in the U.S. do not share data with the CDC, and it is unclear whether attendant quality improvements are due to changed behavior on the part of empowered consumers, or responsive clinicians, or both (Ferris and Torchiana, 2010).

In 2002 the President's Council on Bioethics issued its recommendations for ART, including continued industry self-regulation and federally funded longitudinal 
studies (President's Council on Bioethics, Reproduction and Responsibility: The Regulation of New Biotechnologies) (President's Council on Bioethics, Reproduction and Responsibility: The Regulation of New Biotechnologies, 2002). Arthur Caplan, a noted medical ethicist, proposed that the U.S. Food and Drug Administration should exercise greater control over all new forms of ART; and insurance companies and third-party payers "should pay only for those programs accredited by the American Society for Reproductive Medicine, who are in full compliance..." with the society's guidelines and existing laws. In addition, the National Conference of Commissioners on Uniform State Laws was charged to review the current fragmented state laws and develop model legislation to systematize, as far as possible, legal approaches among states (Caplan, 2007).

In the U.S. the practice of medicine is governed by the 50 states with multiple and diverse regulations affecting reproductive medicine. This has led to growing commercial business entities because of limited regulation. Because ART focuses on babies, and pregnancy is often the result of in vitro fertilization and the creation of embryos, as well as private recruitment of "surrogate mothers", it has proven impossible for the U.S. government to regulate reproductive medicine. Legislators and public health policy makers tread lightly where the rights to privacy and reproductive liberty may have a constitutional basis (Ouellette et al., 2005). Furthermore, the use of the internet, and especially "social websites", have promoted "trade" in surrogacy internationally, making national regulation very difficult. Audi and Chang described the current lack of regulation on ART and reproductive medicine specifically: "with an international network of surrogate mothers and egg and sperm donors, a new industry is emerging to produce children on the cheap and outside the reach of restrictive laws" (Audi and Chang, 2010). George Annas has written elegantly that "If the medical community cannot control assisted reproductive procedures that require the application of medical skills, an unregulated market will determine the price, place, and manner in which human sperm, ova, embryos, and services of surrogate mothers will be made available as well as how family relationships with the resulting babies be will structured". He further observed that the "global baby" has arrived in practice, but neither the legal theory nor medical ethics has kept pace with the globalization of human reproduction (Annas, 2011).
In June 2008 Dr. Michael Kamrava, a California fertility specialist, performed six embryo transfers into Nadya Sulemann and she gave birth to octuplets (the "Octomom"). International attention was focused on the lack of adherence to professional guidelines and lack of governmental regulation of ART and California was labeled "the Wild West" of fertility medicine (Reynolds et al., 2003). On 22 December 2009, the Medical Board of California filed an accusation against Kamrava accusing him of violating Business and Professions codes of "gross negligence, and repeated negligent acts, when he repeatedly transferred an excessive amount of embryos into a patient resulting in an octuplet pregnancy". Further, he never recommended or referred the patient to a mental health professional, although she was single and already had six children. He was also accused of having maintained inadequate records. This initial accusation was amended to further charge him with "incompetence" in his treatment of other patients. On June 2011 the Medical Board revoked his medical license (http://www.mbc.ca/gov/board/media/releases_2011_ 06-_01_kamrava.html). Upon appeal to the Courts, a judge refused to reinstate the medical license in December 2011 ending Dr. Kamrava's medical practice in California (http://www.sacbee.com/2011/12/15/4125570/bidrejected-to-reinstate-octomom.html). This lapse of professional judgment, disregard of professional guidelines, and placing both the mother and eight infants at risk of subsequent disability, incurring substantial costs to the health care system at public expense, stimulated additional calls for government regulation. In addition, recent legal cases involving attorneys arranging for surrogates to have embryos implanted in Ukraine with baby selling activities to vulnerable parents in the U.S. have prompted greater legal oversight of these activities. Dr. Kamrava's decision to disregard professional guidelines while endangering the life of the mother and the eight resulting infants has been the subject of both medical and legal discussion and publications calling for further regulation.

\section{Multiple births and prematurity: ART in the U.S.A.}

One impact of ART in the U.S., is that the twin birth rate rose $2 \%$ in 2009 , to 33.2 twins per 1000 total births. This was another "high" for the nation according to the Centers for Disease Control (Schieve et al., 2002), and far greater than the "natural" rate of twinning. In- 
deed, the rate of twin births has climbed $76 \%$ since 1980 , and $47 \%$ since 1990 . Triplet and higher order multiple birth rate also increased in 2009 to 153.5 per 100,000 live births, and the triplet or greater multiples rose more than $400 \%$ during the 1980 s and 1990 s, peaking at 193.5 in 1998. In 2009, 5905 triplets, 355 quadruplets, and 80 quintuplets and higher-order multiples were born. This pronounced increase in twin and triplet or higher order multiples during the 1980 s and beyond has been associated with older maternal age at childbirth and the expanded use of fertility-enhancing therapies (Hamilton et al., 2011; Wilcox et al., 1996). A recent decline in the rise of triple or higher multiple births may have been influenced by guidelines from the American Society for Reproductive Medicine. These were first issued in 1998 and revised in 2009 and were perhaps intended to reduce the incidence of higher-order multiple gestations. Refinements in assisted reproductive technology procedures have also have been influential, however (Reynolds et al., 2003; Jain et al., 2004).

Maternal age has been rising in the U.S. over the past two decades. Between 2008 and 2009, birth rates declined among women of all age groups under 40 years of age. Although the birth rate for teenagers fell among women aged 15-19 years, the 2009 rate of 39.1 per 1000 women was the lowest reported in nearly the last seven decades. Among women between 20-24 years of age, the birth rate of 96.3 per 1000 women in 2009 was the largest decline since 1973 (Stern et al., 2007), while for women 25-29 the rate was 110.5 per 1000 women a rate that has declined since 1990. For women 30-34 the birth rate has increased from the 1976 to 2007 figure and was 97.7 births per 1000 women in 2009, while in those aged 35-39 the rate is 46.5 per 1000 women which is the second year of decline (2008 and 2009) since a steady increase from 1979 (see Table 1).

Among women, in their 40-44 years of age, the birth rate was 10.1 live births per 1000 women, the highest birth rate reported since 1967, although this rate has been rising steadily over the last 10 years from 7.4 in 1999 (Martinez et al., 2011). The increase in birth rates for women aged 35 and over during the last 20 years has been linked, in part, to the use of fertility-enhancing therapies or ART (National health statistic report, No XX, 2011). In 2009 the American Society of Reproductive Medicine in 2009 issued additional guidelines on the number of embryos transferred (McLernon et al.,

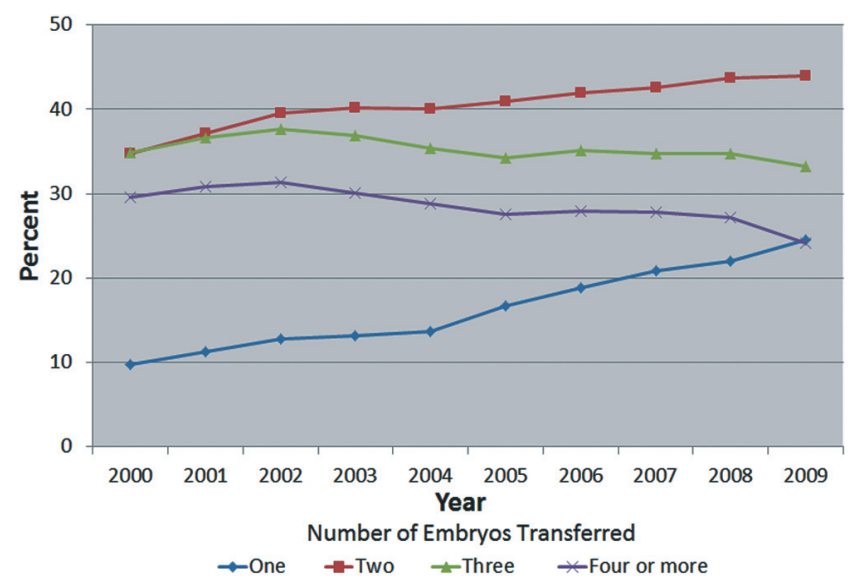

Fig. 1. U.S. Data from Assisted Reproductive Technology, CDC, 2009. Percentage of transfers that resulted in live births using fresh non-donor eggs or embryos, by number of embryos transferred, U.S. 2000-2009 (with permission)

2010; Chandra and Stephen, 2010) - Figure 1, and later in 2011 offered an additional "Committee Opinion: Elective Single Embryo Transfer.” The major conclusions provided by them are as follows: "elective single embryo transfer should be offered to patients with a good prognosis and to recipients of embryos from donated eggs. In vitro fertilization centers should promote elective single embryo transfer, when appropriate, through provider and patient education, and improvements in embryo selection should further increase the application of elective single embryo transfer", along with several additional statements highlighting the results of single embryo transfer compared to double embryo transfer in well-controlled, nonrandomized trials and clinical reports, and noting the improved success of cryo preserved embryos using current technologies (The Practice Committee of the American Society for Reproductive Medicine and the Practice Committee of the Society for Assisted Reproductive Technology, 2009).

A meta-analysis of randomized trials, comparing a single with a double embryo transfer confirms that a single embryo results in a higher chance of delivering a term singleton live birth compared with a double embryo transfer (http://www.asrm.org/uploadedFiles/ASR<). Furthermore, this analysis indicates that "although this strategy yields a lower pregnancy rate than a double embryo transfer in a fresh in vitro fertilization (IVF) cycle, this difference is almost completely overcome by an additional frozen single embryo transfer cycle" (Balaban et al., 2008). Sweden has mandated the single 
Table 1. National summary data from the U.S. of pregnancy success rates -2009

\begin{tabular}{|c|c|c|c|c|c|}
\hline \multirow{2}{*}{ Pregnancy success rates } & \multicolumn{5}{|c|}{ Age of woman (years) } \\
\hline & $<35$ & $35-37$ & $38-40$ & $41-41$ & $43-44+$ \\
\hline \multicolumn{6}{|l|}{ Fresh embryos from nondonor eggs } \\
\hline Percentage of cycles with live births* & 41.2 & 31.6 & 22.3 & 12.4 & 4.9 \\
\hline Percentage of transfers resulting in singleton live births & 30.9 & 27.0 & 21.8 & 14.0 & 6.6 \\
\hline Percentage of pregnancies with twins & 33.4 & 27.4 & 21.5 & 13.4 & 7.5 \\
\hline Percentage of pregnancies with triplets or more & 2.7 & 3.6 & 3.5 & 2.9 & 0.8 \\
\hline \multicolumn{6}{|l|}{ Frozen embryos from nondonor eggs } \\
\hline Percentage of transfers resulting in live births & 35.2 & 30.4 & 25.9 & 21.9 & 15.1 \\
\hline
\end{tabular}

embryo transfer protocol, permitting strictly defined exceptions (mother's age for whom double embryo transfer can be considered and embryo quality) with an overall proportion of deliveries per cycle of $21.9 \%$ (McLernon et al., 2010; Chandra and Stephen, 2010). In a commentary regarding the meta-analysis performed by McLernon and his coworkers (2012), Templeton, cite single embryo transfer rates that vary around the world with Australia, Japan, Sweden, Finland, Belgium and the Netherlands at the top of the list whereas the US at the bottom. He summarizes that "Doctors managing infertile couples are no longer entitled to take risks with the health of the next generation" (Nyboe Andersen et al., 2008).

The greater vulnerability and the compromised outcome of multiple birth gestations compared to singleton gestations is illustrated in Figure 2 (adapted from CDC report 2009) which depict that $35 \%$ of triplet births were born weighing $<1500$ grams compared to $10 \%$ of twins and $1 \%$ of singletons. Since the average twin weigh 960 grams less than the average singleton at birth, triplets typically weigh about $50 \%$ of singletons. What is more concerning is that a shorter gestational age at birth and a smaller size of multiple births create an 8-fold increased risk of dying with the first month of life (cited by CDC 2009 report from the National Center for Health Statistics, unpublished data from the 2007 period linked birth/infant death data set. 2011). Neurodevelopmental outcomes of twins and higher order multiples show poorer cognitive outcomes for twins and that these differences persist even when confounders are taken into

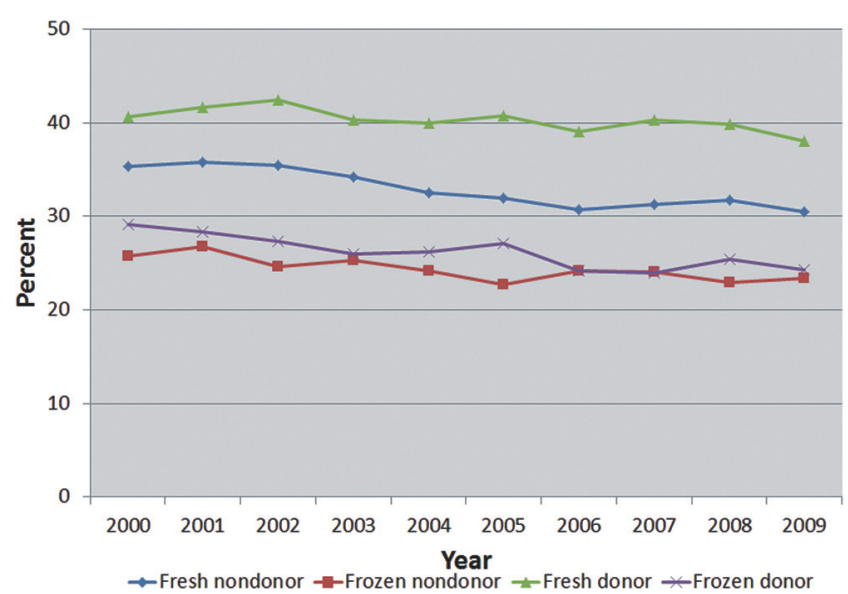

Fig. 2. U.S. Data from Assisted Reproductive Technology, CDC, 2009. Percentage of ART cycles that resulted in multiple-infant live births by type of ART cycle, U.S. 2000-2009 (with permission)

account (Templeton, 2010). Cerebral palsy rates are considerably higher in twins, especially with the death of a co-twin (Cook, 2010).

Commenting on rising rates of preterm birth in the U.S., Lantos and Lauderdale (Ong et al., 2006) specifically focus on the observation that more women are delaying childbearing until they are 30-40 years of age and that these older women have high rates of infertility (Lantos and Lauderdale, 2011), leading to the use of ovarian stimulation drugs and IVF (Van Noord-Zaadstra et al., 1991). These treatments result in higher rates of multiple pregnancies and preterm birth. Although infants conceived using ART account for only $1 \%$ of all births in the US, the proportion of twin and triple or 
more multiple birth attributable to ART is 16 and $44 \%$, respectively (Chandra and Stephen, 1998). Lantos and Lauderdale reflect that the recent drops in preterm birth rates in the U.S. "may reflect an equilibrium, in which advances in prenatal diagnosis, obstetric care of highrisk pregnancies, and neonatal intensive care, along with a new steady state in the demographics of childbearing, and more careful use of assisted reproductive technologies all combine to lead to an optimum balance between reproductive freedom, obstetrical intervention, and perinatal outcomes. "Reports regarding excess premature deliveries following ART, even among singleton deliveries, have been observed in Australia and New Zealand, along with the well-documented increase in preterm infants among twin births (Reynolds et al., 2003; http://www.preru.unsw.edu.au?PRERUWeb.nsf/ reources/ART_2005_06/\$file/art11.pdf). In a comparison of selected twin deliveries with and without ART from Massachusetts, U.S., restricted to mothers of increased socioeconomic status, private health insurance and intermediate/plus prenatal care, twins resulting from ART were less likely than non-ART to be very preterm, $<1500$ grams birth weight, or die prior to hospital discharge (Vitthala et al., 2009).

Following IVF, more fetuses are occasionally discovered than the number of fertilized embryos inserted. Pregnancies resulting from ART procedures carry a twofold or higher risk for producing monozygotic twins, however, this risk varies based on the ART techniques performed. Higher rates of twinning have been reported with other ART forms such as assisted hatching $(0.7 \%)$; ovulation induction (1.2\%); blast transfer (1.7\%); and frozen embryo transfer (3.0\%) (http://www.preru.unsw. edu.au?PRERUWeb.nsf/reources/ART_2005_06/\$file/ art11.pdf). ART is associated with significantly higher rates of dizygotic twin gestations as well as higher order of multiples gestations than expected from "natural" conception. Dizygotic twins comprise $95 \%$ of twin gestations arising from ART, a much higher percentage than dizygotic twins from "natural" conceptions, and more than $50 \%$ of these twin gestations are delivered prior to term, along with higher order multiple birth(s) contribute disproportionately to the need for neonatal intensive care services (Cowan and Demmer, 2007). Data reveal an increased perinatal mortality risk among singletons associated with ART (odds ratio $[\mathrm{OR}]=2.19(95 \% \mathrm{CI}=1.68$ 2.98). Meta-analysis have demonstrated that singletons associated with IVF have an increased risk of preterm birth $(\mathrm{OR}=1.95 \mathrm{CI}=1.73-2.20)$, low birth weight $(\mathrm{R}=$ $1.77,95 \% \mathrm{CI}=1.4-2.22)$, very low birth weight $(\mathrm{OR}=$ 2.7, $95 \% \mathrm{CI}=2.31-3.14)$, and intrauterine growth restriction $(\mathrm{OR}=1.6,95 \% \mathrm{CI}=1.26-2.04)$ (Martin et al., 2007). Each of these added risks often requires intensive care, and thus contributes to resource utilization and hospital days. In vitro fertilization also increases the risk of cerebral palsy due to its association with preterm birth (among both singletons and multiples), although not necessarily because of IVF (Jackson et al., 2004). The financial burden incurred by these infants is enormous, and beyond the scope of this report.

ART is also associated with a higher risk of antepartum hemorrhage than that seen in the overall population. Pregnancies resulting from ART also are significantly more likely to be associated with pre-eclampsia $(4.9 \%$ vs $2.6 \%)$, abruptio placenta $(1.1 \%$ vs $0.6 \%)$, placenta previa (1.0 vs $0.3 \%$ ), hyperemesis gravidarum, anemia and postpartum hemorrhage. Induction of labor is more common $(\mathrm{OR}=2.1,95 \% \mathrm{CI}=1.8-2.4)$ as well as an instrumented delivery $(\mathrm{OR}=2.2,95 \% \mathrm{CI}=1.8-2.6)$. Many infants are more likely to require neonatal personnel for delivery room care. Neonatal intensive care unit (NICU) admission occurs more often (OR $=2.04,95 \%$ $\mathrm{CI}=1.23-3.38)$ following conception with ART (Hvidtjorn et al., 2006; Thomon et al., 2005). Thus the impact of ART for a specific NICU is related to the proportion of birth resulting from ART in a specific region and specific ART modalities used.

Although the correlation between multiple gestation and adverse perinatal outcomes has been well established, most women in the U.S. who choose to use ART elect for multiple embryo transfer. This decision appears to be motivated by a number of factors, including the relatively high cost of ART procedures, which may not be covered by health insurance, and their desire to optimize their chance for pregnancy during a single treatment (Adler-Levy et al., 2007). It is possible that multiple pregnancies may be the preferred outcome for some women with infertility as a survey of fertility clinic patients in the U.S. found that $20 \%$ of women desired multiple gestations in preference to a single birth (Boulet et al., 2008). Nonetheless, it is clear that relative to singleton pregnancies, twin pregnancies, and higher multiples, even more so, face significantly higher risks of perinatal and infant morbidity, regardless of whether 
ART is the method of conception (Wright et al., 2008). Janvier and coworkers (Janvier et al., 2011) point out "it is clear that physicians performing IVF are aware of these risks, but remain willing to perform procedures that increase the risks to mothers and babies." She and her co-authors continue to say that "we think that there are a number of reasons for this ethically unusual situation," including a "perverse economic incentive - for both patients and their providers." Shah and McCrary (Shah and McCrary, 2010) echo these concerns and proposed "stricter regulation" that could promote patient and family welfare while producing healthier babies and maintaining fertility rates." ART techniques led to the phenomenon of fetal reduction. Limiting the number of implanted embryos would reduce the scale of this phenomenon.

\section{Assisted reproduction in Canada}

Universal public funding for ART is not available in Canada, and thus it is estimated that only $15 \%$ of couples affected by infertility can afford IVF or other ART procedures (Nisker, 2008). Only Quebec provides reimbursement for the cost of up to two cycles of IVF treatment (Janvier et al., 2011). A law regulating ART and issues surrounding surrogacy, egg, sperm, and embryo donation was regulated by the Assisted Human Reproduction Act 2004 (http://www/cam;oo/prg/em/ca/laws/stat/sc2004/latest/sc-2004-c-2html). This law lists prohibited activities related to the purchase of donor gametes, sperm, and compensation surrogates. Health Canada indicates "This legislation has three objectives: It prohibits human cloning and other unacceptable activities and seeks to protect the health and safety of Canadians who use ART procedures." It further ensures that ARTrelated research is carried out to find treatments for infertility and "takes place within controlled environments" (www.hc-sc.gc.ca). The legislation established Assisted Reproduction Canada, an agency to implement and enforce this law which licenses all individuals who undertake any controlled activity (those who work with human embryos), and governs the clinical and research activities of medically-assisted human reproduction, and identifies activities that are either prohibited or subject to regulation. This law was challenged, in the Supreme Court of Canada, by the Attorney General of Quebec, joined by the Attorneys General of New Brunswick,
Saskatchewan, and Alberta. The Canadian Supreme Court's majority held that the regulation of reproductive medicine is a provincial power and that it is not constitutional when conducted by the federal government unless it involves prohibited criminal activities (cloning, germline genetic engineering, and commercialization of human gametes and surrogate pregnancy) while IVF and noncommercial gamete donation and surrogacy are under provincial jurisdiction (Supreme Court of Canada Assisted Human Reproduction Act 2010 SCC $61,2010)$. In addition, criminal law prohibitions of the federal act were held that neither physicians nor health care institutions require special licensure to carry out research for medical purposes in assisted reproduction.

Two Canadian technology assessments in 2006 (http://www.health.gov.on.ca/english/providers/ program/ontac/tech/reviews/pdf/revivf101906.pdf) and 2009 (https://www.ihsc.on.ca/programs/infertility) reported IVF and multiple gestation pregnancies. In 2009, the Institute of Health Economics at/in Canada (Anderson and Yan, 2009) sought to clarify the cost burden of multiple pregnancies on health resources and the potential cost impact of ART in Alberta. The 2009 report cites evidence that reducing the number of embryos transferred per IVF cycle to a single embryo transfer reduces the number of multiple births, health complications in the newborn, and the cost associated with multiple gestations. The report found that transferring a single embryo was less costly and just as effective as transferring two embryos for women of 37 years of age or younger. For older women, single embryo transfer was less effective than transferring two embryos, and subsequently, more IVF cycles were required to achieve comparable birth rates. The evidence cited in this report found that reimbursing IVF procedures which transfers fewer embryos was associated with a decrease in the number of multiple births and health services expenses. A greater number of single embryo transfer cycles may be required to produce equivalent results. Janvier et al. (Janvier et al., 2011) reported that if a policy allowing a universal single embryo transfer versus two transfers in as many as one-third of women were in effect for Canada, there would be a saving in the use of NICU resources by 5424 to 7529 fewer NICU patient days of assisted ventilation, and from 35,219 to 42,488 total patient days in an NICU to the Canadian healthcare system. In addition, such 
a policy would spare $30-40$ deaths per year, 34-46 severe intraventricular hemorrhages, and 13-19 retinal surgeries for retinopathy of prematurity if the rates experienced, at the rates of multiple gestations experience, at the Royal Victoria Hospital in Montreal were extrapolated to all of Canada. These authors also believe that transfer of more than a single embryo is "ethically questionable" and argue that physicians should be restrained from so doing by governmental regulation.

\section{Birth defects}

The relationship between ART procedures and birth defects is less clear, and certainly less disclosed (Johnson et al., 2006; Reefhuis et al., 2009). Hansen and coworkers reported that infants conceived by employing ART were more than twice as likely as naturally conceived infants to have a major birth defect (Hansen et al., 2002). Publications from the late 1990s dismissed the increased risk estimates of birth defects because they failed to reach statistical significance. Furthermore, sample sizes were small and noappropriate controls were available (Van Steirteghem, 1998; Kurinczuk and Bower, 1997). In recent years extensive studies and meta-analyses have been conducted utilizing central data banks such as the facility in Western Australia to determine the rate of birth defects occuring with ART (Hansen et al., 2005). National healthcare registries reporting malformations do not exist in the U.S. and data on ART-related births and outcomes has previously been estimated from voluntary fertility clinic reports (Green, 2004). One recent U.S. study accessed data from the National Birth Defects Prevention Study, a populationbased, multicenter, case-control study of birth defects and found that malformations occur more often among infants conceived with ART (Reefhuis et al., 2009) with odds ratios from 2.1 to 4.5 for various major malformations. With larger subject numbers and better controls it is clear that there is an increased risk of malformations with ART (Davies et al., 2012; Wen et al., 2012; Reefhuis et al., 2009; Hansen et al., 2002; Bergh et al., 1999; Wennerholm et al., 2000; Katalinic et al., 2004; Olson et al., 2005). Current results are highly suggestive of increased rates of septal heart defects, cleft lip (with or without cleft palate), esophageal atresia, anorectal atresia, and hypospadius (Table 2) (adapted from Paulson R. Pregnancy outcome after assisted reproductive technology. In: UpToDate, ed. Basow D.W., UpToDate, Waltham, MA, 2012).

The increased risk regarding birth defects could be conveyed as an increased incidence above the standard risk. Alternatively this event rate difference may be explained as the "number needed to harm" or event rate difference/1. Given a baseline prevalence of birth defects of $2-3 \%$ and an increased odds of 2.0, the number of children that are conceived by ART for one additional child to be born with a birth defect is between 33 and 50 (Hansen M. et al., 2005). As assisted reproduction becomes more utilized (and more reimbursed) there is a growing concern that the rates of major birth defects will also rise. Major birth defects that are most often associated with ART include septal heart defects, esophageal atresia, anorectal malformation, and hypospadius (Reefhuis et al., 2009). These defects require major surgical interventions and represent a major burden not only to the infant but also to the health care system. At what level of increased risk is there a duty of the medical profession to advocate for the yet unborn baby? Is a twofold increased risk of birth defects an acceptable risk of ART? There is a concern that the impact of ART on major malformations and birth defects may be either downplayed or not revealed in the informed consent process. (Birth defects and ART are discussed in detail in the following manuscript).

\section{Imprinting disorders}

Genomic imprinting is an epigenetic process that allows some genes to be expressed from only one parental allele while silencing the other parental allele. Specific disorders including Beckwith-Wiedemann Syndrome (BWS), Angelman Syndrome (AS) and others, have been associated with ART. Publications from Europe, the U.S., and Australia have suggested an association between ART and BWS demonstrating more than $90 \%$ of infants with BWS who were born after ART had an imprinting defect. Although limited by their relative rarity and study design, multiple studies from around the globe suggest an association between imprinting disorders and ART, and specifically hypomethylation of maternal allele (Owen and Segars, 2009). Due to the variation of ART protocols and limitations in sample size as well as numerous confounders it has been difficult to rigorously relate an association between imprinting disorders and any 
Table 2. Risk of birth defects in neonates conceived by artificial reproductive technologies and of specific birth defects 2000-2009

\begin{tabular}{|c|c|c|c|c|c|c|}
\hline Author & Year & ART & Control & Results & $\begin{array}{l}\text { Odds } \\
\text { ratios }\end{array}$ & $95 \% \mathrm{CI}$ \\
\hline Wennerholm et al. & 2000 & ICSI & Gen Pop & rate of defects & 1.75 & $1.19-2.58$ \\
\hline Katalinic et al. & 2004 & ICSI & $\mathrm{NC}$ & rate of defects & 1.24 & $1.02-1.5$ \\
\hline Hansen et al. & 2002 & $\begin{array}{l}\text { ICSI } \\
\text { IVF }\end{array}$ & $\begin{array}{l}\mathrm{NC} \\
\mathrm{NC}\end{array}$ & $\begin{array}{l}\text { rate of defects } \\
\text { rate of defects }\end{array}$ & $\begin{array}{l}2.2 \\
2.6 \\
\end{array}$ & $\begin{array}{l}1.3-3.3 \\
1.7-3.0 \\
\end{array}$ \\
\hline Olson et al. & 2005 & IVF & NC & rate of defects & 1.3 & $1.0-1.67$ \\
\hline Reefhuis et al. & 2009 & $\begin{array}{c}\text { IVF } \\
\text { or ICSI }\end{array}$ & $\mathrm{NC}$ & $\begin{array}{l}\text { septal heart defects ASD or ASD + VSD } \\
\text { cleft lip with or without cleft palate } \\
\text { esophageal atresia } \\
\text { anorectal atresia } \\
\text { hypospadias }\end{array}$ & $\begin{array}{l}2.7 \\
2.0 \\
6.8 \\
3.4 \\
4.6\end{array}$ & $\begin{array}{c}1.6-4.8 \\
1.0-4.0 \\
2.8-15.5 \\
1.2-8.3 \\
2.0-10.8\end{array}$ \\
\hline
\end{tabular}

ICSI - intracytoplasmic sperm injection, IVF - in vitro fertilization, NC - natural conception, ASD - atrial septal defects, VSD - ventricular septal defects, Gen Pop - general population

specific ART procedure, and researchers and clinicians have speculated that the increased risk of an imprinting disorder may be due to underlying infertility, ovulation induction with or without IVF or intracytoplasmic sperm injection procedures (Manipalviratn et al., 2009). While the exact mechanism remains to be determined, those undergoing ART need to have disclosure regarding these concerns (Owen and Segars, 2009). (Imprinting disorders are more completely discussed in the following article).

\section{Informed consent and ART}

In none of the publicly available consent forms regarding ART, except for the potentially misleading information about the risk of birth defects or vanishing twin, or imprinting disorders, few consent documents outline the risks to the prematurely born infant including frequent neonatal morbidities, prolonged NICU stay or neuro-developmental handicap or the financial and emotional impact on parents. Recognition that informed consent of highly technical information and the possibility of adverse pregnancy and infant outcomes requires a substantial time commitment on physician's part; nonetheless, remains a duty for the ethical and legal practice of medicine. The American Society for Reproductive Medicine has provided "A Guide for Patients" (e.g. Third Party Reproduction). Other professional societies related to ART provide websites that carefully describe many of the procedures and technical aspects of ART that should assist couples in reaching informed decision- making; however, this information, while useful, does not provide physician- or clinic-specific informed consent.

Professional guidelines and legal doctrine require informed consent that is critical for patient information as well as determination of whether medical malpractice or battery has been committed. Adequate consent requires that patients (and others affected by the procedure) be fully informed about the risks and benefits as well as alternatives of the procedure (Kindregan and McBrien, 2005). A woman and generally her spouse (partner) should have their witnessed signatures on a document that clearly states the nature of the procedure, specific qualifications and nuances related to the procedure, and further explains procedural complications and their impact on the patient. Physician's failure to provide information needed for consent and warn the patient of the potential risks may give rise to legal claims against him/her. Usually specific to the ART, physician may breach their duty to a patient in the course of an ART procedure by failure to provide current information needed to adequately explain the risks to the patient, failure to obtain consent of all interested persons, failure to obtain written consent as required by state statute (often requiring an impartial witness or notary), and failure to warn of the risks associated with ART to the mother, the couple, and potential children. Robertson suggests that "there may be a duty to avoid harm in cases of multiple gestation because some of the children born may have been better off if fewer siblings were 
born in the same IVF cycle" (Robertson, 2004). Indeed, legal opinions recommend that physicians have a duty to inform the patient when risk of a procedure or outcome exceeds that of an ordinary occurrence or risk.

In 1998, a task force in New York revealed wide variability in the information provided in consent documents. It was found that many consent forms do not mention or explain the known or potential risk associated with the drugs used for ovarian stimulation. While most consent forms indicate that ART may result in multiple gestation, a significant number does not mention that multiple gestations entail considerable risk. Few consent forms mention the possibility of fetal reduction that may be recommended in the event of a high-order multiple. The New York task force concluded: "The process of obtaining informed consent to assisted reproduction is seriously deficient. There is considerable evidence that physicians provide incomplete or misleading information about the benefits and risks, particularly the risks associated with multiple gestation" (http://www.health. ny.gov/regulations/task_force/reports_publications /execsum.html). In February 2008, the American Bar Association published a model Act Governing Assisted Reproductive Technology, which also highlights the importance of fully informing the donor, the patient, and any other interested parties of all of the risks associated with ART and multiple pregnancies (www.abanet.org/family /committees/artmodelact.pdf).

A review of certain publicly available consent documents from North Carolina, New York, Georgia, Utah and California illustrate a wide variation regarding the content, specific information, and a description of the risks to the mother and infant from ART. In some states, informed consent on the psychological impact of assisted reproduction including emotional, social, and relationship factors must also be documented, while in other states consent forms are broadly phrased to include "assisted reproduction technologies and techniques". Some consent forms are highly specific with separate consents for stimulation of ovulation, IVF, intracytoplasmic sperm injection, fresh embryo transfer, embryo cyropreservation, assisted hatching, frozen embryo transfer consent, anonymous donor egg use, irrevocable consent regarding donated embryos, and intrauterine insemination (http://www.infertilityspecialist.com).

Some clinics also specifically document the number of embryos desired by the couple (even against medical advice), and others seek consent regarding the disposition of embryos in the case of patient or spousal death, death of the couple, and even divorce. Although a comparison of available consent documents is beyond this review, it is noteworthy that few consent documents comment on the increased risks of birth defects among offspring. Indeed global statements are made that state that "human data suggest that IVF does not increase the risk of congenital anomalies (birth defects) in the resultant offspring" (http://www.infertilityspecialist.com). In terms of choices regarding the number of eggs to be fertilized and the number of embryos to be transferred (or discarded), one consent document reports A) limit fertilization to 3 ova, and transfer all resulting embryos to the uterus, B) fertilize all ova obtained and transfer the best 1 to 3 embryos that result, if embryos remain [in] the laboratory after transfer to the uterus has been completed, we [parents] request that they 1 ) be discarded, 2) donate them for research or other purposes, 3 ) undergo cryopreservation for the potential future intrauterine transfer (http:// healthcare.utah.edu/ucrm/ forms.php).

In contrast, a Canadian consent form "The Informed Consent Booklet for Assisted Reproductive Techniques: Adverse Effects and Risks" (April 9, 2010) from the Ottawa Fertility Center, in Ottawa, Canada provides an extensive list of the benefits and risks of the ART use in their clinic that provides an extensive summary of multifetal gestations and "unknown long-term risk of these treatments including that that could occur in subsequent generations" (www.conceive.ca). (Informed Consent Booklet for Assisted Reproductive Techniques (ART)Adverse Effects and Risks, April 9, 2010, www. conceive.ca (accessed 1/21/2012). In terms of potential impact on the infant, although the risk of prematurity is mentioned, generally these consent documents state that the risk of birth defects is not higher than that among infants conceived naturally, few mention imprinting disorders, and virtually none explains the risks of being born prematurely in terms of prolonged NICU stay or impact on long-term development.

\section{Summary}

This analysis of the current ART practices in Europe and North America provides justification for the establishment of regulations as well as professional guidelines that: 
1) Reduce the number of implanted embryos which may lead to a reduction in neonatal morbidity and mortality.

2) Efforts to provide a more accurate and populationwide data base to estimate the implications for neonatal use of ART, including IVF and ICSI and other procedures on rates of birth defects and imprinting disorders including the number of spontaneous miscarriages, termination of pregnancy, fetal reduction procedures performed, as well as the number of live births per cycles of ART are needed.

3) There is a critical need to compare the economic implications (costs/profits from the procedures and costs for the treatment of these children born as result of ART) within Europe and North America and the cost burden towards health insurance plans or taxpayers within a country.

4) There is a need for a greater public education regarding the burden and benefits of ART on maternal and infant health, both during the neonatal period and thereafter.

5) There should be a requirement for longitudinal developmental follow-up of children born after ART as well as their offspring to determine the possible epigenetic influences of these procedure(s) in subsequent generations.

6) Payment for ART services within a country need to be estimated in order to adhere with professional guidelines and/or governmental regulation.

7) While honoring the concept of reproductive liberty and individual rights in choosing ART, for example over adoption of children already born, to create a family, the societal impact of ART needs to be evaluated in terms of family well-being and adjustment.

8) The concept of surrogacy (especially paid surrogacy for an unrelated couple) needs to be carefully evaluated by governmental authorities in terms of whether the infants delivered by a non-citizen will have "citizenship" bestowed on the basis of the genetic parentage versus gestational "parentage" or, in the case of donated embryos, citizenship of the parents assuming the care of the infants born from these gestations.

9) "Medical Tourism" couples or women for the purpose of undergoing ART should be highly discouraged and available only when such services are not provided within their own country.
10) The use of Natural Procreative Technology (Naprotechnology) should also be considered by couples with infertility diagnosis, and treatment of conditions resulting in infertility which may be corrected to restore normal reproductive function.

11) Advances should continue to improve current ART procedures focused on incubation techniques that do not expose the developing embryo to hypo- or hypermethylation conditions that might stimulate epigenetic alterations in gene expression.

\section{References}

Adashi E.Y., Wyden R. (2011) Public reporting of clinical outcomes of assisted reproductive technology programs. JAMA 306: 1135-1136.

Adler-Levy Y., Lunenfeld E., Levy A. (2007) Obstetric outcome of twin pregnancies conceived by in vitro fertilization and ovulation induction compared with those conceived spontaneously. Eur. J. Obstet. Gynecol. Reprod. Biol. 133: 173-178.

Anderson C., Yan C. (2009) Assisted reproductive technologies: a literature review and database analysis institute of health economics. Edmonton, Alberta, pp. 1-84.

Annas G. (2011) Assisted reproduction - Canada's supreme court and the "Global Baby". N. Engl. J. Med. 365(5): 459463.

Audi T., Chang A. (2010) Assembling the global baby. Wall Street Journal, December 10: D1-D2.

Balaban B., Urman B., Alta B., Isiklar A., Larman M.G., Hamilton R. et al. (2008) A randomized controlled study of human day 3 embryo cryopreservation by slow freezing or vitrification: vitrification is associated with higher survival, metabolism and blastocyst formation. Hum. Reprod. 23: $1976-1982$.

Basso O., Olsen J. (2005) Subfecundtity and neonatal mortality: longitudinal study within Danish national bithkohort. BMJ 330: 393-394.

Bergh T., Ericson A., Hillensjo T., Nygren K. et al. (1999) Deliveries and children born after in-intro fertilization in Sweden 1982-95: a retrospective cohort study. Lancet 354: 1579-1585.

Blickstein I., Keith L. (2002) Jatrogenic multiple pregnancy. Semin. Neonatol. 7(3): 169.

Blickstein I. (2002) Normal and abnormal growth of multiples. Semin. Neonatol. 7(3): 177.

Boulet S.L., Schieve L.A., Nannini A., Ferre C., Devine O., Cohen B., Zhang S., Wright V., Macaluso M. (2008) Perinatal outcomes of twin births conceived using assisted reproduction technology: a population-based study. Hum. Reprod. 23(8): 1941-1948.

Caplan A. (2007) A modest proposal (letter). Hastings Center Rep. 37(6): 4-5. 
Chandra A., Stephen E.H. (1998) Imparied fecundity in the United States: 1982-1995. Fam. Plann. Perspect. 30: 34-42.

Chandra A., Stephen E.H. (2010) Infertility service use among U.S. women: 1995 and 2002. Fertil. Steril. 93(3): 725-736.

Cook J.L. et al. (2011) Assisted reproductive technology - related multiple births: Canada In an Intarnational Contex. JOGC 27(2): 159-166.

Cook R.W.I. (2010) Does neonatal and infant neurodevelopmental morbidity of multiples and singletons differ?Sem. Fetal Neonatal. Med. 15: 362-366.

Cowan J.M., Demmer L.A. (2007) Assisted reproductive technology and preimplantationgeneticdiagnosis: impact on the fetus and newborn. NeoRev. 8: e127-132.

Davies M.J., Moore V.W., Willson K.J., Van Essen P., Priest K., Scott H., Haan E.AS., Chan A. (2012) Reproductive technologies and the risk of birth defects. N. Engl. J. Med. 366(19): 1803-1813.

de Mouzon J., Goossens V., Bhattacharya S., Castilla J.A., Ferraretti A.P., Korsak V., Kupka M., Nygren K.G., Nyboe Andersen A., European IVF-monitoring (EIM), Consortium, for the European Society of Human Reproduction and Embryology (ESHRE) (2010) Assisted reproductive technology in Europe, 2006: results generated from Euro pean registers by ESHRE. Hum Reprod. 25: 1851-1862.

Denbow M. et al. (2000) Placental angioarchitecture In monochorionic twin pregnancies: relationship to fetal growth, fetofetal transfusion syndrome, and pregnancy outcome. Am. J. Obstet. Gynecol. 182: 417-426.

Directive 2004/23 - Official Journal of the European Union, L102,07/04/2004 P.0048-0058

Engmann L. et al. (2001) Trends in the incidence of births and multiple births and the factors that determine the probability of multiple births after IVF treatment. Hum. Reprod. 16(12): 2598-2605.

Ferris T.G., Torchiana D.F. (2010) Public Release of clinical outcomes data: online CABG report cards. N. Engl. J. Med. 363(17): 1593-1595.

Finnstrom O., Kallen B. (2011) Maternal and child outcome after in vitro fertilization - a review of 25 years of population-based data from Sweden. Acta Obstet. Gynecol. Scand. 90: 494-500.

Green G. (2004) Risks of birth defects and other adverse outcomes associated with assisted reproductive technology. Pediatrics 114: 256-259.

Halliday J.L. et al. (2010) Increased risk of blastogenesis birth defects, arising In the first 4 weeks of pregnancy, after assisted reproductive technologies. Hum. Reprod. 25: 59-65.

Hamilton B.E., Ventura M.A., Osterman M.J.K., Kirmeyer S., Mathew T.J., Wilson E. (2011) Births: final data for 2009. Nat. Vital Statist. Rep. 60(1): 1-35.

Hansen M., Boer C., Milne E., de Klerk N., Kurinczuk J. (2005) Assisted reproductive technologies and the risk of birth defects - a systematic review. Hum. Reprod. 20: 328-338.

Hansen M., Kurinczuk J., Bower C. (2002) The risk of major birth defects after intracytoplasmic sperm injection and in vitro fertilization. N. Engl. J. Med. 346: 725-730.
Helmehorst F.M. et al. (2004) Perinatal outcomes of singletons and twins after assisted conception: a systematic review of controlled studies. BMJ 328: 261-265.

Hvidtjorn D., Grove J., Schendel D.E. et al. (2006) Cerebral palsy among children born after in vitro fertilization: the role of preterm delivery - a population-based, cohort study. Pediatrics 118: 475-482.

Jackson R.A., Gibson K.A., Wu Y.W., Croughan M.S. (2004) Perinatal outcomes in singletons following in vitro fertilization: a meta-analysis. Obstet. Gynceol. 103: 551-563.

Jain T., Missmer S.A., Hornstein M.D. (2004) Trends in embryo-transfer practice and in outcomes of the use of assisted reproductive technology in the United States. N. Engl. J. Med. 350(16): 1639-1645.

Janvier A., Spelke B., Barrington K. (2011) The epidemic of multiple gestations and neonatal intensive care use: the cost of irresponsibility. J. Pediatr. 159(3): 409-413

Johnson J., Hartman T., Colby C. (2006) Developmental and genetic outcomes in children conceived through assisted reproductive technologies. NeoRev. 12: 615-625.

Kallen B. et al. (2005) In vitro fertilization in Sweden: obsteric characteristics, maternal morbidity and mortality. BJOG 112: 1529-1535.

Kallen B. et al. (2010) Congenital malformations in infants born after in vitro fertilization in Sweden. Birth Defects Res. A 88: 137-143.

Katalinic A., Rosch C., Ludwig M. (2004) Pregnancy course and outcome after intracytoplasmic sperm injection: a controlled, prospective cohort study. Ferti. Steril. 81: 1514-1520.

Kindregan C.P., McBrien M. (2005) Assisted reproductive technology: a lawyer's guide to emerging law and science. Chicago, American Bar Association.

Kurinczuk J., Bower C. (1997) Birth defects in infants conceived by intracytoplasmic sperm injection: an alternative interpretation. BMJ 315: 1260-1265.

Land J.A., Evers J.L.H. (2003) Risk and complications is assisted reproduction techniques: Report of an ESHRE consensus meeting. Hum. Reprod. 18: 455-457.

Lantos J.D., Lauderdale D.S. (2011) What is behind the rising rates of preterm birth in the united states? Rambam Maimonides Med. J. 2(4): e0065-0075.

Little S.E., Ratcliffe J., Caughey A.B. (2006) Cost of transferring one through five embryos per in vitro fertilization cycle from various payer perspectives. Obstet. Gynceol. 108: 593-601.

Manipalviratn S.D., Cherney A., Segars J. (2009) Imprinting disorders and assisted reproductive technology. Fertil. Steril. 91(2): 305-315.

Martin J.A., Stern J.E., Cedars M.I., Jain T., Klein N.A., Beaird C.M., Grainger D.A., Gibbons W.E. (2007) Assisted reproductive technology practice patterns and the impact of embryo transfer guidelines in the United States. Fertil. Steril. 88(2): 275-282.

Martinez G., Copen C.E., Abma J.C. (2011) Teenagers in the United States: Sexual activity, contraceptive use, and childbearing, 2006-2010 National Survey of Family Growth: 
National Center for Health Statistics. Vital Health Stat 23(31). Retrieved November 11, 2011 from http://www. cdc.gov/nchs/data/series/sr_23/sr23_031.pdf

McLernon D.J., Harrild K., Bergh C., Davies M.J., de Neubourg D., Dumoulin J.C.M. et. al. (2010) Clinical effectiveness of elective single versus double embryo transfer: meta-analysis of individual patient data from randomized trials. BMJ; 341: c6945.

National health statistic report, No XX. Hyattsville, MD: National Center for Health Statistic, 2011 volume 1, natality.

Nisker J. (2008) Distributive Justice and infertility treatment in Canada. J. Obstet. Gynecol. Canad. 30(5): 425-431.

Nyboe Andersen A., Goossens V., Ferraretti A.P., Bhattacharya S., Felberbaum R., deMouzon J. et al. (2008) $A s$ sisted reproductive technology in Europe 2004: results generated drom European registers by ESHRE. Hum. Reprod. 23: 756-771.

Nygren K.G., Nyboe Andersen A. (2001) Assisted reproductive technology in Europe, 1997. Results generated European register by ESHRE. Hum. Reprod. 16: 384-391.

Nygren K.G., Nyboe Andersen A. (2002) Assisted reproductive technology in Europe, 2001. Results generated European register by ESHRE. Hum. Reprod. 20: 1158-1176.

Olson C., Keppler-Noreuil K., Romitte P., Budelier W. (2005) In vitro fertilization is associated with an increase in major birth defects. Fertil. Steril. 84: 1308-1315.

Ong S.S., Zamora J., Kahn K.S., Kilby M.D. (2006) Prognosis for the co-twin following single-twin death: a systematic review. BJOG 113: 992-998.

Ouellette A., Caplan A., Carroll K., Fossett J.W., Bjarnadottir D., Schieckle D., McGee G.L. (2005) Lessons from across the pond: assisted reproductive technology in the United Kingdom and the United States. Am. J. Law Med. 31: 419444.

Owen C.M., Segars J.H. (2009) Imprinting disorders and assisted reproductive technology. Semin. Reprod. Med. 27(5): 417-428.

Papiernik E. (2008) Termination of pregnancy among very Preterm births and its impact on very Preterm mortality: results from ten european population-based cohorts in the MOSAIC study. BJOG 115: 361-368.

President's Council on Bioethics, Reproduction and Responsibility: The Regulation of New Biotechnologies (2002), available at http://www.bioethics.gov/reports/reproductionand responsibility/_pcbe_final_reproduction_and_responsibi lity.pdf accessed 1/6/2012.

Reefhuis J., Honein M., Schieve L., Correa A. et al. (2009) Assisted reproductive technology and major structural birth defects in the United States. Hum. Reprod. 24: 30-36.

Revinis E.R., Johnson L.A. (1994) Multiple gestation. In: Neonatology: Pathophysiology and management of the newborn, ed. Avery G.B. et al., Lippincott Company, p. 417-426.

Reynolds M. et al. (2003) Trends in multiple births conceived using assisted reproductive technology United States 1997-2000. Pediatrics 111: 1159-1162.

Robertson J.A. (2004) Procreative liberty and harm to offspring in assisted reproduction. Am. J. Law Med. 7: 10.
Schieve L.A., Meikle S.F., Ferre C., Peterson H.B., Jeng G., Wilcox L.S. (2002) Low and very low birth weight in infants conceived with use of assisted reproductive technology. N. Engl. J. Med. 346: 731-737.

Shah S.I., McCrary S.V. (2010) Assisted Reproductive Technologies: impact on neonatology and a call for reform. J. Neonatal. Perinatal. Med. 3: 77-84.

Stern J.E., Cedars M.I., Jain T., Klein N.A., Beaird C.M., Grainger D.A., Gibbons W.E. (2007) Assisted reproductive technology practice patterns and the impact of embryo transfer guidelines in the United States. Fertil. Steril. 88(2): 275-282.

Supreme Court of Canada Assisted Human Reproduction Act 2010 SCC 61, [2010] 3 S.C.R. 457. December 22, 2010.

Templeton A. (2010) Elective single versus double embryo transfer. BMJ 341: c7083. doi: 10.1136/bmj.c7083

The Practice Committee of the American Society for Reproductive Medicine and the Practice Committee of the Society for Assisted Reproductive Technology (2009) Guidelines on number of embryos transferred. Fertil. Steril. 92(5): 1518-1519.

Thomon F., Shanbhag S., Templeton A., Bhattacharya S. (2005) Obstetric outcome in women with subfertility. BJOG 112: 632-637.

United States Supreme Court (1977) Carey v. Population Services international, 431 US 678(97S) Ct 2010.

United States Supreme Court (1905) Jacobsen v Massachusetts, 197 U.S. 11.

Van Noord-Zaadstra B.M., Looman C.W.N., Alsbach H., Habbema J.D.F., teVelde E.R., Karbaat J. (1991) Delaying childbearing: effect of age on fecundity and outcome of pregnancy. BMJ 302: 1361-1365.

Van Steirteghem A. (1998) Outcome of assisted reproductive technology. N. Engl. J. Med. 338: 194-145.

Vitthala S., Gelbaya T.A., Brison D.R., Fitzgerald C.T., Nardo L.G. (2009) The risk of monozygotic twins after assisted reproductive technologies: a systematic review and metanalysis. Hum. Reprod. Update 15: 45-55.

Wen J., Jiang J., Ding C., Dai J., Liu Y., Xia Y., Liu J., Hu Z. (2012) Birth defects in children conceived by in vitro fertilization and intracytoplasmic sperm injection: a meta-analysis. Fertil. Steril. Apr. 3 [epub ahead of print].

Wennerholm U., Bergh C., Hamberger L. (2000) Incidence of congenital malformations in children born after ICSI. Hum. Reprod. 15: 944-948.

Wilcox L.S., Kiely J.L., Melvin C.L., Martin M.C. (1996) Assisted reproductive technologies: Estimates of their contribution to multiple births and newborn hospital days in the United States. Fertil. Steril. 65(2): 361-366.

Wright V.C., Chang J., Jeng G., Macaluso M. (2008) Assisted reproductive technology surveillance - United States 2005. MMWR Surveill Summer 57: 1-23.

\section{Websites}

American Bar Association Model Act Governing Assisted Reproductive Technology, www.abanet.org/family/comm ittees/artmodelact.pdf (accessed 1/21/2012). 
Centers for Disease Control and Prevention. Assisted Reproductive Technology (ART) http://www.ced.gov/ART/ (accessed $1 / 20 / 2012$ ).

Deutsch L. The Sacemento Bee, (http://www.sacbee.com/ 2011/12/15/4125570/bid-rejected-to-reinstate-octo mom.html) (accessed 1/5/2012).

Executive Summary of Assisted Reproductive Technologies: Analysis and Recommendations for Public Policy of the New York Department of Health. Available at http: //www.health.ny.gov/regulations/task_force/reports_pu blications/execsum.htm (accessed 1/21/2012).

"Good clinical treatment in assisted reproduction - an eshre position paper", http://www.eshre.eu/ESHRE/English /Guidelines-Legal/ESHRE-Position-Papers.

Health Canada Assisted Human Reproduction www.hc-sc.gc.ca (accessed1/6/2012).

http://conventions.coe.int/Treaty/html/164.html

http://www.asrm.org/uploadedFiles/ASR < Content/New and Publications/Practice Guidelines/Committee Opinions/ eSET-prinable.pdf (accessed 1/4/2012).

http://www/cam;oo/prg/em/ca/laws/stat/sc-2004/latest/sc2004-c-2html (accessed 1/6/2012).

http://www.prawoimedycyna.pl/index.php?str=artykul\&id=250

Informed Consent Booklet for Assisted Reproductive Techniques (ART)-Adverse Effects and Risks, April 9, 2010 , www.conceive.ca (accessed 1/21/2012).
Medical Advisory Secretariat. In vitro fertilization and multiple pregnancies. Toronto: Ontario Health Technology Advisory Committee: 2006 available at http://www. health.gov.on.ca/english/providers/program/ontac/tech /reviews/pdf/rev ivf 101906.pdf (accessed on 1/8/2012)

Miller J.F. et al. (1980) Fetal loss after implantation. Lancet $11,554$.

Paulson R. Pregnancy outcome after assisted reproductive technology. UpToDate, 2011, http://www. uptodate.com /store

Reproductive Care Center Consent Document, http://www. infertilityspecialist.com (accessed 1/21/2012).

Seeking life through ART: the cost of treatment. London (ON): London Health Sciences Centre; 2009 available at: http://www.ihsc.on.ca/programs/infertility

The Medical Board of California, News Release 2011 06-01 Kamravaavailable at http://www.mbc.ca/gov/board/media /releases_2011_06-_01_kamrava.html (accessed 1/5/2012).

Utah Center for Reproductive Medicine, Section III, Consent Forms updated May 2011, University of Utah Health Care http://healthcare.utah.edu/ucrm/forms.php (accessed 1/21/2011).

Wang Y., Dean J., Sullivan E.A. Assisted reproduction technology in Australia and New Zealand 2005. Available at http://www.preru.unsw.edu.au?PRERUWeb.nsf/resour ces/ART_2005_06/\$file/art11.pdf (accessed 1/4/2012). 